(CRP) levels, perception of uncontrolled disease and presence of swollen and tender joints compared to patients without axial involvement. A higher proportion of PsA patients with axial manifestations were treated with a biologic compared with those without axial involvement $68.4 \%$ vs $57.3 \%$ (Table 1). Patients with axial involvement showed a higher impairment of their quality of life compared to those without axial manifestations by a worse higher mean (SD) Psoriatic Arthritis Impact of Disease 12-item questionnaire (PSAID12) score (5.0 [2.4] vs 2.7 [2.2], respectively). In terms of disease control more patients with axial manifestations presented with moderate to high disease activity (DAPSA $>14: 65.7 \%$ vs $36.8 \%$, respectively) and did not meet the MDA criteria for remission $(89.5 \%$ vs $42.7 \%$, respectively) (Figure 1 ).

Conclusion: PsA patients with axial manifestations presented with a higher burden of disease and showed a worse disease control compared to those without axial involvement.

Table 1. Baseline demographic and clinical characteristics

\begin{tabular}{|c|c|c|c|}
\hline & $\begin{array}{c}\text { With axial } \\
\text { manifestations } \\
(n=38)\end{array}$ & $\begin{array}{l}\text { Without axial } \\
\text { manifestations } \\
\quad(n=274)\end{array}$ & $\begin{array}{c}\text { PsA } \\
(n=312)\end{array}$ \\
\hline Age (years), mean (SD) & $53.1(10.4)$ & $54.1(12.4)$ & $54.0(12.2)$ \\
\hline Sex (male), n (\%) & $17(44.7 \%)$ & $153(55.8 \%)$ & $170(54.5 \%)$ \\
\hline Time since diagnosis (years), mean (SD) & $13.6(10.1)$ & $10.1(8.8)$ & $10.5(9.0)$ \\
\hline $\begin{array}{l}\text { Time from onset of symptoms to diagnosis } \\
\text { (years), mean (SD) }\end{array}$ & $4.3(6.1)$ & $2.8(4.8)$ & $3.0(5.0)$ \\
\hline $\begin{array}{l}\text { Presence of concomitant diseases, mean } \\
\text { (SD) }\end{array}$ & $26(68.4 \%)$ & $166(60.6 \%)$ & $192(61.5 \%)$ \\
\hline Anemia, n (\%) & $3(7.9 \%)$ & $7(2.6 \%)$ & $7(2.2 \%)$ \\
\hline Anxiety, n (\%) & $6(15.8 \%)$ & $9(3.3 \%)$ & $1(0.3 \%)$ \\
\hline Asthma, n (\%) & $2(5.3 \%)$ & $7(2.6 \%)$ & $1(0.3 \%)$ \\
\hline Depression, n (\%) & $6(15.8 \%)$ & $1(0.4 \%)$ & $1(0.3 \%)$ \\
\hline Dyslipidemia, n (\%) & $3(7.9 \%)$ & $8(2.9 \%)$ & $9(2.9 \%)$ \\
\hline Hypertension, n (\%) & $3(7.9 \%)$ & $7(2.6 \%)$ & $9(2.9 \%)$ \\
\hline $\begin{array}{l}\text { Others (excluding skin psoriasis, uveitis, or } \\
\text { IBD), } \mathrm{n}(\%)\end{array}$ & $3(7.9 \%)$ & $17(6.2 \%)$ & $19(6.1 \%)$ \\
\hline Presence of HLA-B*27+, n (\%) & $6(15.8 \%)$ & $28(10.2 \%)$ & $34(10.9 \%)$ \\
\hline CRP levels (mg/l), mean (SD) & $7.3(11.3)$ & $4.6(6.5)$ & $4.9(7.3)$ \\
\hline $\begin{array}{l}\text { Patient perceived disease control (PASS), } \\
\mathrm{n}(\%)\end{array}$ & $30(78.9 \%)$ & $228(83.5 \%)$ & $258(83.0 \%)$ \\
\hline Presence of swollen (SJC $\geq 1), n(\%)$ & $22(57.9 \%)$ & $117(42.7 \%)$ & $139(44.6 \%)$ \\
\hline Presence of tender joints $(T J C \geq 1), n(\%)$ & $14(36.8 \%)$ & $74(27.0 \%)$ & $88(28.2 \%)$ \\
\hline Patients treated with biological & $26(68.4 \%)$ & $157(57.3 \%)$ & $183(58.7 \%)$ \\
\hline
\end{tabular}

COPD, chronic obstructive pulmonary disease; CRP, C-reactive protein; HLA-B*27, human leukocyte antigen B27; IBD, inflammatory bowel disease; PASS, patient acceptable symptom state; PsA, psoriatic arthritis; SD, standard deviation; SJC, swollen joint counts; TJC, tender joint counts.

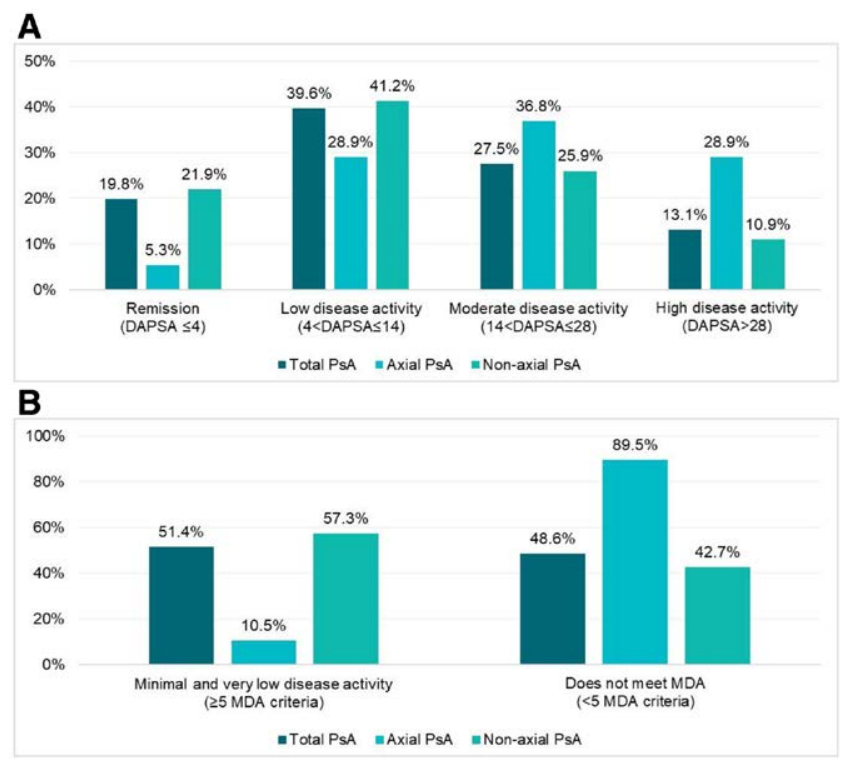

Figure 1. Disease status according to clinical phenotype of PSA A) Disease activity according to DAPSA B) Disease activity according to MDADAPSA, Disease Activity in Psoriatic Arthritis; MDA, Minimal Disease Activity; PsA, psoriatic arthritis.

Acknowledgements: We thank to MIDAS group investigators and patients included in the study.
Disclosure of Interests: Eugenio de Miguel Speakers bureau: AbbVie, Novartis, Pfizer, MSD, BMS, UCB, Roche, Grunental, Janssen, Sanofi., Paid instructor for: Janssen, Novartis, Roche, Consultant of: AbbVie, Novartis, Pfizer, Galapagos Grant/research support from: Abbvie, Novartis, Pfizer, Jordi Gratacos-Masmitja Speakers bureau: During the course of the year I have received funding in relation to courses and / or conferences, and / or have participated as a speaker or in advisory boards from: MSD, Pfizer, AbbVie, Janssen Cilag, Novartis, Lilly and Amgen., Consultant of: During the course of the year I have received funding in relation to courses and / or conferences, and / or have participated as a speaker or in advisory boards from: MSD, Pfizer, AbbVie, Janssen Cilag, Novartis, Lilly and Amgen., Grant/research support from: During the course of the year I have received a private grand from Pfizer.

I have not received any private influence in the elaboration of the contents of this talk., Ana Paula Cacheda: None declared, José M. Rodríguez-Heredia Speakers bureau: Amgen, Novartis, Sanofi, Consultant of: Amgen, Biogen, Fresenius, MSD, Janssen, Roche, Novartis, Pfizer, Sanofi, Adela Gallego Speakers bureau: During the course of the year I have received funding in relation to courses and / or conferences, and / or have participated as a speaker or in advisory boards from: MSD, Pfizer, AbbVie, Janssen, Novartis, Lilly, Amgen and Sanofi.

I have not received any private influence in the elaboration of the contents of this talk., Grant/research support from: During the course of the year I have received funding in relation to courses and / or conferences, and / or have participated as a speaker or in advisory boards from: MSD, Pfizer, AbbVie, Janssen, Novartis Lilly, Amgen and Sanofi.

I have not received any private influence in the elaboration of the contents of this talk., Emma Beltrán Speakers bureau: Abbvie, Bristol, Celgene, Janssen, Lilly, MSD, Novartis, Pfizer, Roche and UCB, Consultant of: Abbvie, Bristol, Celgene, Janssen, Lilly, MSD, Novartis, Pfizer, Roche and UCB, Beatriz Font Ramos Employee of: Novartis employee, Carlos Sastré Employee of: Novartis employee, Cristina Sanabra Employee of: Novartis employee.

DOI: 10.1136/annrheumdis-2021-eular.2041

\section{POS0979 ASSOCIATION BETWEEN HIGHER INTAKE OF CARBOHYDRATES AND FREE SUGAR WITH HIGHER DISEASE ACTIVITY IN PATIENTS WITH AXIAL SPONDYLOARTHRITIS}

V. Rios Rodriguez ${ }^{1}$, M. D'urso ${ }^{1}$, C. Höppner ${ }^{1}$, F. Proft ${ }^{1}$, M. Protopopov' ${ }^{1}$, J. Rademacher ${ }^{1}$, B. Muche ${ }^{1}$, S. Lüders ${ }^{1}$, H. Haibel ${ }^{1}$, M. Verba ${ }^{1}$, J. Sieper ${ }^{1}$, D. Poddubnyy $1,2 .{ }^{1}$ Charité - Universitätsmedizin Berlin, Campus Benjamin Franklin, Gastroenterology, Infectiology and Rheumatology, Berlin, Germany; ${ }^{2}$ Deutsches Rheuma-Forschungszentrum Berlin (DRFZ), ein Institut der Leibniz-Gemeinschaft, Epidemiology, Berlin, Germany

Background: Diet has been previously described as an impact factor on the course of rheumatic diseases, such as rheumatoid arthritis and systemic lupus erythematosus (SLE). It has been previously reported that dietary sugar intake may contribute to subclinical inflammation and disease activity in SLE. However, there is very little investigation on the possible association between nutritional parameters and their influence on spondyloarthritis (SpA).

Objectives: To investigate the possible impact of nutritional parameters on the disease activity in patients with SpA.

Methods: Patients with radiographic axial SpA and starting a biological ther apy were recruited between 2015 and 2019 in an extension of the prospective German Spondyloarthritis Inception Cohort (GESPIC). Dietary habits were collected at baseline using the country-specific validated food frequency questionnaire (FFQ) developed for the use in the German Health examination Survey for Adults 2008-2011. The FFQ includes questions about the frequency and amount of 53 food items, consumed during the past 4 weeks, and enabled to compute individual mean consumptions of foods in grams per day. Total energy intake (in Kcal per day) and nutritional parameters: carbohydrates, free sugars, total fats, saturated fats, mono and poly-unsaturated fats, proteins and dietary fiber, were calculated for each patient using a nutrition organization software and the database of Federal Food Code (Bundeslebensmittelschlüssel), version 3.02. Disease activity measures (BASDAI, CRP and ASDAS), as well as height, weight and body mass index (BMI) were assessed at baseline before starting the biological treatment.

Results: A total of 104 patients from 129 patients with axial SpA enrolled in the cohort were included in this nutritional analysis. The mean age (mean \pm SD) was $37.0 \pm 11.0$ years old with symptoms duration of $11.3 \pm 9.9$ years, $68.3 \%$ were males and $86.5 \%$ were HLA-B27 positive. Patients presented BMI of $25.1 \pm 4.3 \mathrm{~kg} / \mathrm{m}^{2}$ BASDAI 5.6 \pm 1.4 , CRP $14.0 \pm 18.2 \mathrm{mg} / \mathrm{l}$, and ASDAS $3.5 \pm 1.0$.

In the univariable and multivariable regression analysis, a higher energy intake and carbohydrates were associated with higher disease activity, measured by ASDAS, BASDAI and CRP. This association was attributable to the full intake of carbohydrates and specifically to the total of free sugars (monosaccharides 
and disaccharides) and the decrease of dietary fiber as shown in the multivariable analyses (Figure 1). This effect was independent of age, sex, smoker status and BMI.

Conclusion: A higher intake of carbohydrates and a higher consumption of free sugars are associated with higher disease activity in patients with AS.
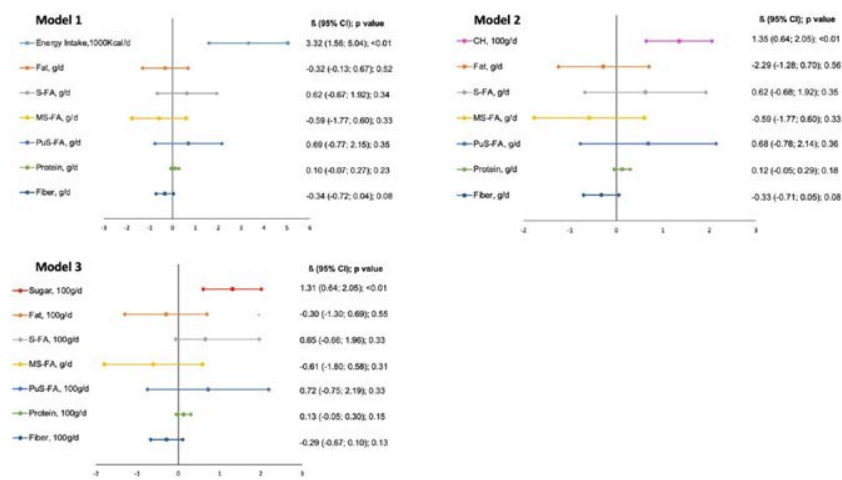

Figure 1. Multivariable linear regression analysis of the association between CRP and nutritional parameters in patients with radiographic axial SpA $(n=104)$, adjusted for age, sex, body mass index and smoker status. Model 1 included variable of total energy intake, model 2 included variable of total intake of carbohydrates $(\mathrm{CH})$ and model 3 included variable of freesugar (monosaccharides and disaccharides).

$\mathrm{B}$, linear regression coefficient; $\mathrm{CH}$, carbohydrates; $\mathrm{Cl}$, confidence interval; MS-FA, monosaturated fatty acids; PuS-FA, polyunsaturated fatty acids, S-FA, saturated fatty acids.

Disclosure of Interests: None declared.

DOI: 10.1136/annrheumdis-2021-eular.2052

\section{POS0980 \\ ANALYSIS OF PRIMARY CARE CONSULTATION PATTERNS TO AID DIAGNOSIS OF AXIAL SPONDYLOARTHRITIS - AN EXPLORATORY CASE SERIES}

M. Al-Attar ${ }^{1}$, W. J. Gregory ${ }^{1,2}$, J. Mcbeth ${ }^{3,4}$, W. Dixon ${ }^{1,3,4} \cdot{ }^{1}$ Rheumatology Department, Salford Royal NHS Foundation Trust, Salford, United Kingdom ${ }^{2}$ Faculty of Health, Psychology and Social Care, Manchester Metropolitan University, Manchester, United Kingdom; ${ }^{3}$ Centre for Epidemiology Versus Arthritis, University of Manchester, Manchester, United Kingdom; ${ }^{4} \mathrm{NIHR}$ Manchester Musculoskeletal Biomedical Research Centre, Central Manchester University Hospitals NHS Foundation Trust, Manchester, United Kingdom

Background: Patients with Axial Spondyloarthritis (AxSpA) often suffer a significant delay to diagnosis. This is associated with poorer outcomes in quality of life, functional capabilities and work productivity [1]. These patients are frequent consulters to primary care in the years preceding rheumatology referral [2]. We hypothesise that analysis of primary care consultation patterns may identify as-yet undiagnosed disease, and suggest that implementing an automated diagnostic algorithm may support early action in primary care.

Objectives: To undertake a preliminary exploration of primary care consultation patterns in patients with a delayed diagnosis of $\mathrm{AxSpA}$ and identify themes for further research.

Methods: The study was run in Salford, UK, where unique linkage exists across electronic health records (EHR) from primary and secondary care. A dataset of patients with AxSpA was obtained from 2018-2020 hospital physiotherapy clinic records. Ten patients with a time to diagnosis $\geq 5$ years were randomly selected for this exploratory analysis. Diagnostic delay was calculated based on rheumatology clinic letter documentation. Age, sex, and HLA-B27 status were recorded.
All "Problem" codes from the primary care EHR up to the point of diagnosis were manually reviewed.

Results: Age at diagnosis was 32-49 years with seven males and three females. Seven were HLA-B27 positive. The average delay to diagnosis was 15.8 years (range 5-30).

On average, patients had 15 primary care consultations (range 5-24) between first coded AxSpA-related symptom and rheumatology referral. Around half of these codes were potentially AxSpA-related (for example, see Figure 1).

Six patients had a coded history of back pain. Two patients presented with other axial symptoms, including: rib pain, MSK chest pain and sciatica.

Five patients presented with peripheral joint symptoms, including: ankle pain shoulder pain, knee problem, pain in arm, medial epicondylitis elbow, hip pain and groin pain. Of these, four had multiple presentations and three had a previous visit with axial pain

Two patients had uveitis preceding axial symptoms. One patient had periphera joint symptoms (hip pain) preceding uveitis.

Inconsistent codes were used for the same problem presenting at different times in nine cases, including: back pain, backache, low back pain, lower back pain.

Other relevant codes were used in seven cases, including: stiffness, arthritis, saw physiotherapist and referred to pain clinic.

Figure 1 illustrates the consultation pattern for a male patient who first presented to primary care with back pain at the age of 35. Despite a relatively typical presentation, his diagnosis was made incidentally 10 years later after an ESR was checked for unrelated reasons. He was significantly disabled in function at the point of being referred to rheumatology.

Figure 1: Example of a patient's primary care consultation pattern

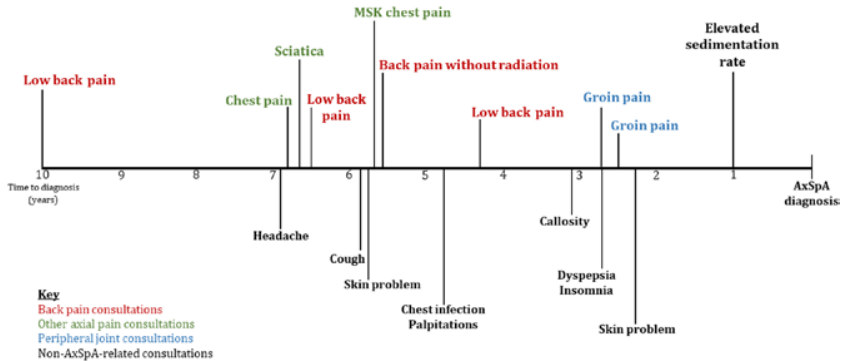

Conclusion: Our preliminary analysis suggests that patients with a delayed diagnosis of AxSpA have repeated primary care visits with potentially recognisable symptoms of their disease. These findings support the feasibility of future automated detection, with areas of focus including recognition of non-back pain axial symptoms, extra-articular manifestations, and peripheral joint symptoms.

Whilst half of presentations were not directly AxSpA-related, modern machine learning techniques have the ability to explore whether the pattern or frequency of these consultations are relevant to identifying undiagnosed disease. Such methods can also highlight patterns obscured by extensive data sets and inconsistent coding, with opportunity for implementation back into primary care.

\section{REFERENCES:}

[1] Redeker I et al. Determinants of diagnostic delay in axial spondyloarthritis: an analysis based on linked claims and patient-reported survey data. Rheumatology (Oxford) 2019;58:1634-8.

[2] Yi E et al. Clinical, Economic, and Humanistic Burden Associated With Delayed Diagnosis of Axial Spondyloarthritis: A Systematic Review. Rheumatol Ther. 2020;7(1):65-87

Disclosure of Interests: None declared.

DOI: 10.1136/annrheumdis-2021-eular.2124 